\title{
THE DEVELOPMENT OF THE REVISED PAVLOVIAN TEMPERAMENT SURVEY IN ENGLAND: CONTINUING RESEARCH*
}

\author{
W. J. Corulla,${ }^{1} \dagger$ J. Strelau, ${ }^{2}$ A. Angleitner, ${ }^{3}$ and W. Ruch ${ }^{4}$ \\ ${ }^{1}$ Department of Psychology, University of Newcastle upon Tyne, NE1 7RU England, ${ }^{2}$ Faculty of \\ Psychology, Department of Individual Differences, University of Warsaw, Poland, ${ }^{3}$ Department of \\ Psychology, University of Beilefeld, Germany and ${ }^{4}$ Psychologisches Institut der Universität Düsseldorf, \\ Germany
}

(Received 17 April 1992)

\begin{abstract}
Summary-The 252-item Pavlovian Temperament Survey-Revised (PTS-R) was adapted for English speaking countries and then administered to 622 subjects ( 315 female and 307 male). Items for the final 160-item version were selected on the basis of the criteria outlined by Strelau et al. (1990; European Journal of Personality, 4, 209-235). A 78-item short form was also developed. Both inventories are scored on a 4-point I ikert scale.
\end{abstract}

\section{INTRODUCTION}

The Strelau Temperament Inventory (STI; Strelau, 1972) was developed as a self-report measure of the nervous system properties elaborated by Pavlov $(1951,1955)$. It should be pointed out here that the name (STI) was not given to the inventory by Strelau. He called it the TI and it was Western workers who associated Strelau's name with the STI. This point is important because the inventory seeks to provide a diagnostic tool of Pavlovian typology and not Strelau's (Strelau, 1983) Regulative Theory of Temperament and by using Strelau's name in the STI's title some confusion arises. It is therefore more appropriate to refer to the instrument as the Pavlovian Temperament Survey (PTS). Therefore, throughout this paper STI will be used when referring to the original inventory and PTS will be used when referring to the revised versions.

Pavlov's concept of type of nervous system (TNS) will not be discussed in any great detail here since Pavlov's typology has been reviewed many times (see Strelau, Angleitner, Bantelmann \& Ruch, 1990; Strelau, 1983; Corulla, 1989 for a review of current thinking on Pavlovian typology). However, it would be useful (1) to re-state Pavlov's descriptions of the properties, (2) to briefly introduce the additions to Pavlovian typology by neo-Pavlovian typologists, and (3) to re-state the hypotheses which generated much of the Western interest in Pavlovian typology.

Strength of Excitation (SE), was described as the capacity of the nervous system to endure long-lasting or short-lived but intense stimulation. Strength of Inhibition (SI), was described as the system's capacity for conditioned inhibition and is manifested in the capacity to refrain from action, to delay action or to interrupt action. Mobility of Nervous Processes (MO) was described as the system's capacity for rapid changes in behaviour following rapid changes in environmental stimulation. Balance (B) of nervous system processes is described and estimated by the ratio of SE/SI.

Perhaps the most noted neo-Pavlovians are Teplov (1963) and Nebylitsyn (1963). The work of these authors has been discussed in detail elsewhere (cf. Strelau, 1983; Corulla, 1989; Strelau, Angleitner \& Ruch, 1989). It will therefore suffice to say that this group (the Moscow Group) developed and/or elaborated many psychophysiological and psychophysical measures for the diagnosis of nervous system properties in man and to remind the reader of the additional properties postulated by these workers which include, as the most important: Concentratability, Activatability, Dynamism and Lability. It is important to point out that the STI and the PTS do not purport to be measures of these neo-Pavlovian additions to Pavlovian typology.

*This is part of a paper presented at the First International Workshop of the European Association of Personality Psychology (EAPP) on Cross-Cultural Research on Temperament, Nieborow, Poland, 7-12 September 1991.

$\dagger$ To whom correspondence should be addressed. 
Since its advent, the STI has gained a degree of international popularity and has been used many times in research programmes (Carlier, 1985; Stelmack, Kruidenier \& Anthony, 1985; Corulla, 1989).

Much of the interest in Pavlovian typology and the STI stems from the Eysenckian (Eysenck, 1966) hypothesis that there exists a commonality between Eysenckian and Pavlovian typology. The substance of this hypothesis is that the Strong TNS resembles the Extravert while the Weak TNS resembles the Introvert and Gray's (Gray, 1964) arousability postulate which states that low arousability resembles the Strong TNS and high arousability resembles the Weak TNS.

However, research by Strelau et al. (1989) found that the STI lacks the psychometric characteristics necessary to accept this instrument as a valid measure of Pavlovian typology. In order to rectify this situation, Strelau et al. (1990) embarked upon a revision of the STI.

The first step in this programme of the inventory's revision was the generation of a 377-item pool (152 items for the SE scale, 113 items for the SI scale, 112 items for the MO scale along with 15 original items from the STI). Step two involved scrutinizing the items for each of the respective scales. Only those items that were fully agreed upon by four independent judges were finally selected. This procedure resulted in a 252 -item pool ( $\mathrm{SE}=90$ items, $\mathrm{SI}=84$ items, $\mathrm{MO}=78$ items). The authors point out that this version contains more items than intended. The following criteria were employed for a revised and reduced PTS; an item was deleted if (1) corrected item-total correlation was $<0.15$, (2) item correlation with the corresponding scale was less than the correlation with the other scales, $c^{-(3)}$ an item correlation with its respective scale was not significant. This procedure resulted in 86 items being excluded from the 252 -item pool leaving a total of 166 items in the final full version.

A short form of the inventory (PTS-S) was also developed by selecting the four best items of each component based upon item-total correlation. This procedure resulted in an 84-item PTS-S.

Since the construction of the PTS, the present author has become involved in an international research programme, the aim of which is the construction and validation of the PTS-S in several different countries.

The first step in the present study was the adaptation of the 252-item PTS, so as to make it more comprehensible in English speaking countries, in which English is the first language.

Having accomplished this, a project aimed at reducing the 252 -item inventory was undertaken employing the criteria set out by Strelau et al. (1990).

\section{METHOD}

The adapted English version of the 252-item PTS was administered to $622 S$ s ( 315 female and 307 male). The age range for the female sub-sample was 17 to 63 years with a mean age of 28.9 , $\mathrm{SD}=14.1$. The age range for the male sub-sample was 17 to 65 years with a mean age of 30.2 , $\mathrm{SD}=12.8$. The combined sample consisted of university students, college students, nurses, police personnel, technicians, construction workers and a variety of miscellaneous workers in employment. Therefore the present sample was fairly heterogeneous.

\section{RESULTS AND DISCUSSION}

Cronbach alpha was computed for each component of the three scales using the SPSSx Reliability sub-routine (SPSS, 1983). This sub-routine provides item to item correlation, item to scale corrected alpha and coefficient alpha.

This procedure resulted in the deletion of 100 items based upon the criteria established by Strelau et al. (1990). That is, 43 items were deleted because they did not reach significant correlations with their respective scales, 41 items fell below the cut off criterion of 0.15 for corrected item-total correlation and 16 items correlated more strongly with other scales than they did for their own putative scale. Facets SE4 and MO5 were eliminated because their respective scale reliabilities were below $0.30(0.28$ and 0.24 , respectively). It is interesting to note that these are the same facets lost in the Strelau et al. (1990) study. However, item 136 from facet SE4 (item 10 on the English version 
PTS) correlated quite strongly with SE5 (0.73) and so was retained on this facet. This resulted in the retention of 52 SE items, 51 SI items and 46 MO items; totalling 149 iterns. 3 additional items were retained (12, 74 and 86 - the present PTS) as possible social desirability (SD) items on the grounds of over $90 \%$ endorsement. From this analysis only these three items from the 252 -item PTS emerged as possible SD items. Therefore, 8 items having the highest loadings on the EPQ-R Lie scale were incorporated into the English version. This results in a 160 -item version for English speaking countries.

The next stage in the present study was the calculation of means, standard deviations and alpha coefficients for the scales and facets for males and females, separately. These are shown in Table 1.

An inspection of Table 1 will show that the means and standard deviations obtained in the present study are well in keeping with the Strelau et al. (1990) study. Sex differences have been found with males scoring significantly higher on SE and SI than females. There was no difference found for the MO scale. Most studies using the original STI (Strelau, 1983; Corulla, 1989) have reported sex differences between these scales in the same direction. Therefore this result is not very surprising. The alpha reliabilities obtained in the present study are also in keeping with those reported by Strelau et al. (1990). It is also noted that these alphas are higher than those obtained for the original STI (Corulla, 1989). Of particular interest is the reliability of the SE scale for both sexes ( 0.91 and 0.87 compared with 0.80 and 0.73 , PTS and STI for males and females, respectively). It will also be noted that the SD scale shows a moderately high internal consistency $(0.79$ and 0.77 , males and females, respectively).

Presented in Table 2 are the intercorrelations betwcen the facets, scales and social desirability (SD) for the male sub-sample $(n=307)$.

Presented in Table 3 are the intercorrelations between the facets, scales and SD for the female sub-sample $(n=315)$.

An inspection of Tables 2 and 3 shows that almost all of the correlations are somewhat stronger for the male sub-sample. Of particular interest are the correlations with SD for male $S$ s with the other variables. Almost all of the these are stronger than those obtained for the female sub-sample. It was noted that the mean for SD was also higher for males. Combining these two findings a tentative explanation can be offered for this result. It may be the case that the male $S \mathrm{~s}$ in the present sample care slightly more about what others think of them, and in so thinking tend to score higher on SD scales than do females. Thus, a stronger commonality between SD and temperamental characteristics may exist for male $S$ s. It will also be noted that for both sub-samples SE, SI and MO correlate to some extent. The correlation between MO and SE is stronger than with SI for both males and females. That these scales seem to be oblique rather than orthogonal is not surprising given Pavlov's original postulate. Pavlov stated that it is a combination of the nervous system properties which determine type of nervous system.

Table 1. Means, standard deviations, $t$-statistic and alpha separately for males and females $(n=622,315, \mathrm{~F}$ and $307 \mathrm{M})$

\begin{tabular}{|c|c|c|c|c|c|c|c|c|c|}
\hline \multirow[b]{2}{*}{ Facet/s } & \multirow[b]{2}{*}{ No. items } & \multicolumn{2}{|c|}{ Male } & \multicolumn{2}{|c|}{ Female } & \multirow{2}{*}{$\begin{array}{c}\text { Male } \\
\text { Alpha }\end{array}$} & \multirow{2}{*}{$\begin{array}{c}\text { Female } \\
\text { Alpha }\end{array}$} & \multirow[b]{2}{*}{$t$} & \multirow[b]{2}{*}{$P$} \\
\hline & & $\bar{X}$ & SD & $\bar{X}$ & $\mathrm{SD}$ & & & & \\
\hline SE1 & 6 & 4.20 & 1.37 & 3.15 & 1.94 & 0.62 & 0.64 & & \\
\hline SE2 & 8 & 3.62 & 2.09 & 2.72 & 1.83 & 0.65 & 0.63 & & \\
\hline SE3 & 10 & 5.81 & 3.11 & 4.69 & 2.74 & 0.78 & 0.74 & & \\
\hline SE5 & 12 & 5.20 & 2.59 & 4.83 & 2.02 & 0.87 & 0.81 & & \\
\hline SE6 & 9 & 4.15 & 1.91 & 3.71 & 1.97 & 0.81 & 0.77 & & \\
\hline SE7 & 7 & 3.84 & 2.02 & 3.64 & 1.41 & 0.62 & 0.67 & & \\
\hline SE & 52 & 26.71 & 13.06 & 22.87 & 12.01 & 0.91 & 0.87 & 5.07 & 0.001 \\
\hline SI 1 & 11 & 7.46 & 2.31 & 6.34 & 2.07 & 0.63 & 0.60 & & \\
\hline SI2 & 9 & 5.31 & 2.98 & 5.21 & 1.97 & 0.68 & 0.65 & & \\
\hline SI3 & 8 & 5.58 & 2.11 & 4.97 & 2.48 & 0.71 & 0.63 & & \\
\hline SI4 & 11 & 7.21 & 2.58 & 6.98 & 2.12 & 0.67 & 0.62 & & \\
\hline SI5 & 12 & 6.26 & 2.08 & 6.11 & 2.67 & 0.81 & 0.76 & & \\
\hline SI & 51 & 32.03 & 12.08 & 29.47 & 11.27 & 0.87 & 0.81 & 3.06 & 0.01 \\
\hline MO1 & 12 & 10.51 & 2.98 & 10.49 & 2.79 & 0.76 & 0.71 & & \\
\hline MO2 & 12 & 9.67 & 3.02 & 9.37 & 2.98 & 0.81 & 0.78 & & \\
\hline MO3 & 12 & 8.92 & 2.71 & 8.81 & 2.67 & 0.69 & 0.64 & & \\
\hline MOS & 10 & 7.21 & 2.98 & 7.03 & 3.01 & 0.81 & 0.74 & & \\
\hline MO & 46 & 36.28 & 11.70 & 35.70 & 11.47 & 0.87 & 0.82 & 0.01 & NS \\
\hline SD & 11 & 13.71 & 4.78 & 11.98 & 3.92 & 0.79 & 0.77 & 3.35 & 0.01 \\
\hline
\end{tabular}


Table 2. Intercorrelations between scales and facets for males (decimal points omitted,

\begin{tabular}{lrrrr}
\multicolumn{5}{c}{$r=0.14, P<0.01)$} \\
\hline SE & SE & SI & MO & SD \\
SI & 1 & & & 27 \\
MO & 16 & 1 & & 42 \\
SE1 & 62 & 25 & 1 & 22 \\
SE2 & 27 & 09 & 35 & 1 \\
SE3 & 41 & 08 & 21 & 15 \\
SE5 & 46 & 10 & 27 & 36 \\
SE6 & 51 & 17 & 48 & 27 \\
SE7 & 49 & 14 & 32 & 37 \\
SI1 & -12 & 36 & 37 & 10 \\
SI2 & 18 & 37 & 24 & 19 \\
SI3 & 21 & 28 & 22 & 33 \\
SI4 & 16 & 46 & 11 & 40 \\
SI5 & 22 & 35 & 19 & 21 \\
MO1 & 35 & 19 & 54 & 61 \\
MO2 & 28 & 08 & 38 & 34 \\
MO3 & 36 & 22 & 57 & 40 \\
MO4 & 24 & 28 & 36 & 22 \\
\hline
\end{tabular}

Table 3. Intercorrelations for the female subsample (decimal points omitted, $r=0.14$,

\begin{tabular}{lrrrr}
\multicolumn{5}{c}{$P<0.01)$} \\
\hline & SE & SI & MO & SD \\
\hline SE & 1 & & & 16 \\
SI & 12 & 1 & & 32 \\
MO & 47 & 20 & 1 & 18 \\
SE1 & 30 & -07 & 40 & 09 \\
SE2 & 38 & 09 & 18 & 13 \\
SE3 & 41 & 12 & 22 & 27 \\
SE5 & 36 & 14 & 41 & 21 \\
SE6 & 48 & 11 & 27 & 33 \\
SE7 & 52 & 26 & 35 & 14 \\
SI1 & 08 & 32 & -08 & 21 \\
SI2 & 16 & 41 & 13 & 30 \\
SI3 & -13 & 23 & 20 & 23 \\
SI4 & 11 & 41 & 19 & 32 \\
SI5 & 18 & 37 & 10 & 17 \\
MO1 & 27 & 16 & 27 & 41 \\
MO2 & 33 & -02 & 61 & 26 \\
MO3 & 26 & 23 & 53 & 32 \\
MO4 & 20 & 12 & 36 & 19 \\
\hline
\end{tabular}

Shown in Table 4 are the intercorrelations between the 15 facets of the 160 -item PTS.

As can be seen from Table 4, there are quite a number of significant correlations (given that for $622 \mathrm{Ss}$ the critical value of $r=0.11$ to reach 0.01 significance). However, this magnitude is much too low to suggest a really significantly strong relationship. It will be noted that while some significant correlations have been obtained between the SE, SI and MO facets, the strongest correlations are between the facets of their respective scales. For example, the SE facets have stronger correlations among themselves than they do with the other facets. This result is in keeping with those reported by Strelau et al. (1990). It is important to recall the above Pavlovian statement when inspecting these intercorrelations.

A short form of the English version PTS was also developed. This was done to keep within the international agreement on this research and, more importantly, for some types of research a short scale is more appropriate than the long form.

The criterion of selecting items based on the highest item-scale correlation was employed. This procedure resulted in an SE scale consisting of 24 items, an SI scale consisting of 24 items, an MO scale consisting of 24 items and an SD scale consisting of 6 items. The English version PTS-S thus consists of 78 items.

Presented in Table 5 are the scale means, standard deviations and Cronbach alpha obtained for the combined sample $(n=622)$.

It can clearly be seen from Table 5 that the means and alpha coefficients are well within the range of those reported by Strelau et al. (1990). It is worth pointing out, however, that Cronbach's alpha is reduced on all short scales and this is almost certainly due to the reduction in scale size. The magnitude of the reliabilities suggests that the short form may be a useful instrument, when time limits dictate.

Table 4. Intercorrelations between the 15-point English version (combined sample $n=622$, decimal points omitted, $r=0.11, P<0.01$ )

\begin{tabular}{|c|c|c|c|c|c|c|c|c|c|c|c|c|c|c|c|}
\hline & SE1 & SE2 & SE3 & SE5 & SE6 & SE7 & SII & $\mathrm{SI} 2$ & SI3 & SI4 & SI5 & $\mathrm{MO} 1$ & MO2 & MO3 & MO4 \\
\hline$\overline{\mathrm{SE} 1}$ & 1 & & & & & & & & & & & & & & \\
\hline SE2 & 10 & 1 & & & & & & & & & & & & & \\
\hline SE3 & 35 & 27 & 1 & & & & & & & & & & & & \\
\hline SE5 & 23 & 51 & 20 & 1 & & & & & & & & & & & \\
\hline SE6 & 40 & 16 & 28 & 51 & 1 & & & & & & & & & & \\
\hline SE7 & 27 & 12 & 25 & 37 & 50 & 1 & & & & & & & & & \\
\hline SIl & -08 & -09 & -10 & 00 & 00 & -03 & 1 & & & & & & & & \\
\hline SI2 & -02 & 00 & -05 & 16 & 12 & 14 & 31 & 1 & & & & & & & \\
\hline SI3 & 08 & 00 & -06 & 17 & 11 & 13 & 37 & 28 & 1 & & & & & & \\
\hline SI4 & 09 & -00 & 00 & -09 & 16 & 12 & 45 & 35 & 33 & 1 & & & & & \\
\hline S15 & 01 & 03 & 01 & 10 & -10 & 17 & 19 & 41 & 30 & 42 & 1 & & & & \\
\hline MOI & 20 & 21 & 25 & 27 & 20 & 37 & 01 & 17 & 14 & 15 & 23 & 1 & & & \\
\hline $\mathrm{MO2}$ & 31 & 19 & 31 & 22 & 31 & 28 & 00 & 20 & 10 & 06 & 11 & 42 & 1 & & \\
\hline MO3 & 19 & 25 & 19 & 37 & 32 & 26 & -06 & 16 & 26 & 09 & 09 & 51 & 40 & 1 & \\
\hline MO4 & 17 & 18 & 27 & 25 & 19 & 20 & 12 & 14 & 17 & 10 & 19 & 55 & 38 & 42 & 1 \\
\hline
\end{tabular}


Table 5. Combined sample scale means, standard deviations and

\begin{tabular}{lcccc}
\multicolumn{5}{c}{ alphas } \\
\hline Scale & No. items & $\bar{X}$ & SD & Alpha \\
\hline SE & 24 & 10.01 & 4.67 & 0.77 \\
SI & 24 & 13.23 & 5.78 & 0.72 \\
MO & 24 & 15.21 & 3.89 & 0.77 \\
SD & 6 & 5.36 & 2.18 & 0.68 \\
\hline
\end{tabular}

\begin{tabular}{lrrrr}
$\begin{array}{l}\text { Table 6. Intercorrelations between the } 4 \\
\text { scales }\end{array}$ & $\begin{array}{l}\text { (combined sample, } \\
r=0.11,\end{array}$ & $n=622$, \\
& SE & SI & MO & SD \\
\hline & 1 & & & \\
\hline SE & 24 & 1 & & \\
SI & 62 & 21 & 1 & \\
MO & 62 & 35 & 41 & 1 \\
SD & 27 & 35 & \\
\hline
\end{tabular}

Table 7. Short and long scale intercorrelations shown on the diagonal $(s=$ short

\begin{tabular}{lcccc}
\hline & SEs & SIs & MOs & SDs \\
\hline SE & 94 & & & \\
SI & 35 & 88 & & \\
MO & 62 & 22 & 95 & \\
SD & 27 & 21 & 32 & 93 \\
\hline
\end{tabular}

Presented in Table 6 are the intercorrelations between the 4 short scales.

It can be seen quite clearly that this pattern of correlations is close to those reported above and by Strelau et al. (1990).

For completeness, intercorrelations were run between the short scale scores and the long form scale scores. These are shown in Table 7.

These rather strong correlations suggest that the short form can be used quite legitimately when needed and that they are measuring to a very large extent the properties measured by the PTS.

\section{CONCLUSION}

The results reported above suggest that the English version of the PTS represents a welcome improvement on the original STI in terms of its psychometric properties. This has been shown in the somewhat higher internal consistency of the new scales, improved distributions and pattern of correlations.

It is also worthwhile pointing out that $96 \%$ of the respondents said that the 4-point Likert scale used was easier to use and seemed much more appropriate than a forced choice yes/no response format. This was found by asking the $S$, in a covering letter, for comments concerning the response format.

The next stage in the English series of studies is a project aimed at validation of the PTS. At present, a large study is underway in which approx. $750 \mathrm{~S}$ s from the 5 British socio-economic classifications are completing the following inventories; the PTS, Eysenck's revised EPQ-R (Eysenck, Eysenck \& Barrett, 1985), the revised Dimensions of Temperament Survey (DOTS-R; Windle \& Learner, 1986), the Sensation Seeking Scale (Form V; SSS; Zuckerman, 1979), the Questionnaire for the Structure of Temperament (QST; Rusalov, 1989), The EASI (Buss \& Plomin, 1975) and the UWIST Mood Adjective Checklist (Matthews, Jones \& Chamberlain, 1990).

Copies of the English version PTS-R and the short form, along with scoring keys are available from the senior author upon request.

\section{REFERENCES}

Buss, A. \& Plomin, R. (1975). A temperament theory of personality development. New York: Wiley-Interscience.

Carlier, M. (1985). Factor analysis of Strelau's questionnaire and an attempt to validate some of the factors. In Strelau, J., Farley, F. H. \& Gale, A. (Eds), The biological foundations of personality and behavior. Washington: Hemisphere.

Corulla, W. J. (1989). The relationships between the Strelau Temperament Inventory, sensation seeking and Eysenck's dimensional system of personality. Personality and Individual Differences, 10, 161-173.

Cronbach, L. (1951). Coefficient alpha and the internal structure of tests. Psychometrika, 16, 297-334.

Eysenck, H. J. (1966). Conditioning, introversion-extraversion and the strength of the nervous system. In Nebylitsyn, V. D. (Ed.), Symposium 9: Physiological bases of individual psychological differences. Proceedings of the 18th International Congress of Psychology. Moscow.

Eysenck, S. B. G., Eysenck, H. J. \& Barrett, P. (1985a). A revised version of the Psychotism scale. Personality and Individual Differences, 6, 21-29.

Eysenck, S. B. G., Pearson, P., Easting, G. \& Allsopp, J. F. (1985b). Age norms for impulsiveness, venturesomeness and empathy in adults. Personality and Individual Differences, 6, 613-619. 
Gray, J. A. (1964). Strength of the nervous system and levels of arousal: a reinterpretation. In Gray, J. A. (Ed.), Pavlov's typology: Recent theoretical and experimental developments from the laboratory of $B$. M. Teplov. Oxford: Pergamon Press.

Matthews, G., Jones, D. \& Chamberlain, G. (1990). Refining the measurement of mood: The UWIST Mood Adjective Checklist. British Journal of Psychology, 81, 17-42.

Nebylitsyn, V. D. (1963). The structure of the basic properties of the nervous system. Voprosy Psikhologii, 4.

Pavlov, 1. P. (1951). Complete Works (2nd Edn). Leningrad: SSSR Academy of Sciences.

Pavlov, I. P. (1955). Selected Works. (Translated by S. Belsky) Moscow: Foreign Languages Publishing House.

Ruch, W., Angleitner, A. \& Strelau, J. (1991). The Strelau Temperament Inventory-Revised (STI-R): Validity studies. European Journal of Psychology, 5, 287-308.

Rusalov, V. M. (1989). Object-related and communicative aspects of human temperament: a new questionnaire of the structure of temperament. Personality and Individual Differences, 10, 817-827.

SPSS Inc. (1983). A Complete Users Guide to SPSSx Language and Operations. New York: McGraw-Hill Book Company.

Stelmack, R., Kruidenier, B. \& Anthony, S. (1985). A factor analysis of the Eysenck Personality Questionnaire and the Strelau Temperament Inventory. Personality and Individual Differences, 6, 657-659.

Strelau, J. (1972). A diagnosis of temperament by non-experimental techniques. Pol. Psychol. Bull., 3, 97-105.

Strelau, J. (1983). Temperament-personality-activity. London: Academic Press.

Strelau, J., Angleitner, A. \& Ruch, W. (1989). Strelau Temperament Inventory (STI): General review and studies based on German samples. In Spielberger, C. D. \& Butcher, J. N. (Eds), Advances in personality assessment Vol. 8. Hillside, NJ: Erlbaum.

Strelau, J., Angleitner, A., Bantelmann, J. \& Ruch, W. (1990). The Strelau Temperament Inventory-Revised: theoretical considerations and scale development. European Journal of Personality, 4, $209-235$.

Teplov, B. M. (1955). The study on types of higher nervous activity and psychology. Voprosy Psikhologii, 1, 36-41.

Teplov, B. M. (1963). New data on investigation of human nervous system properties. In Teplov, B. M. (Ed.), Typological features of higher nervous activity in man. Vol. 3. Moscow.

Windle, M. \& Lerner, R. M. (1986). Reassessing the dimensions of temperamental individuality across the life span: The Revised Dimensions of Temperament Survey (DOTS-R). Journal of Adolescent Research, 1, 213-230.

Zuckerman, M. (1979). Sensation seeking: Beyond the optimal level of arousal. New Jersey: Lawrence Erlbaum. 